\title{
Teatro de Bonecos ou Teatro de Animação?
}

\author{
Puppet Theater or Animation Theater?
}

Paulo Balardim ${ }^{1}$ 


\section{Resumo}

A discussão proposta investiga o recurso da animação de objetos, materiais ou corpo objetificado, em decorrência das transformações vivenciadas pelo tradicional Teatro de Bonecos na segunda metade do século XX. Ao longo do texto, emerge o questionamento sobre os motivos/sentidos das palavras na designação dessa forma teatral e o modo como apontam para uma nova percepção dos processos utilizados nas construções poéticas. Para isso, o texto reflete sobre $o$ percurso que assinala o desenvolvimento de um novo entendimento das especificidades dessa arte no Brasil, apontando algumas de suas características.

Palavras-chave: Teatro de Animação; teatro de bonecos; objeto animado

\section{Abstract}

From the changes the tradition of Puppetry Theater has experienced in the second half of the century this article aims at investigating resources of animated objects, materials or the objectified body beyond semantic questioning. Throughout this arti-cle I investigate issues around motives and senses of words used to designate ac-tions in Puppet Theater and the ways the vocabulary might points to new perception of processes applied increative processes. In order to reach the question of vocabu-laries we sketch the tradition of this art form in Brazil and underline its main charac-teristics.

Keywords: Animation Theater; Puppet Theater; Animated Object

ISSN: 1414.5731

E-ISSN: 2358.6958 


\section{O boneco como representação}

Para compreendermos a escolha de uma nova terminologia adotada no Brasil mais frequentemente a partir dos anos 1990, é necessário remontarmos ao entendimento do que representa, ou representou, o boneco teatral e de como evoluíram essas formas de representação.

É importante inteirar-se de que a representação da imagem humana pelo próprio homem se apresenta mais do que uma reprodução artística, mas também como uma forma de reflexionar sobre sua essência e sobre sua existência. Figuras esculpidas, entalhadas, acopladas ao corpo do homem ou projetadas em sombras, acompanham nossa civilização desde seu primórdio e deixam vestígios presentes não apenas em sítios arqueológicos, mas também na construção simbólica do mundo. Presente nos ritos antigos, o caráter hierático atribuído aos bonecos e determinados objetos foi utilizado como um modo de manifestar e ascender angústias e conflitos individuais e sociais. Os estudos do pesquisador, jornalista e escritor francês Charles Magnin (1793-1862) já apontavam que o boneco, mais do que mero brinquedo infantil, desde cedo foi induzido ao movimento, numa tentativa de expressar outra natureza, regida por forças invisíveis e incompreensíveis, e com elas se comunicar. O uso de recursos mecânicos para atribuir propriedades sobrenaturais às esculturas vem de longa data: Segundo o autor, encontramos os primeiros registros desse uso nos escritos de Heródoto (485?-420 a.C.), que descreve a estatuária móvel utilizada na festa de Osíris, no Egito (Magnin, 1862, p. 9-10). Na evolução dessa relação com o sagrado, temos um largo histórico no qual o homem buscou ocultar tanto os mecanismos utilizados para mover os bonecos quanto a força ativa na sua manipulação. Tanto o processo de animação quanto o manipulador, em diversas culturas, tornaram-se tabus e esse conhecimento era destinado apenas para alguns escolhidos, aos quais era delegada a tarefa de intermediar e conduzir as negociações com o outro mundo. Mas, em paralelo a sua utilização nos círculos cerimoniais e mágicos, os bonecos também assumiram um caráter popular, satírico e contestatório, tanto em meio à aristocracia quanto em eventos do povo. A expressão das figuras animadas não diligenciava somente por promover o sagrado, mas se esforçava também para realizar o divertimento público, embora quase sempre fosse preservado o ocultamento de seus operadores (Magnin, 1862).

Perdendo seu vínculo com o sagrado, pouco a pouco, a animação de bonecos foi adquirindo maior espaço como manifestação teatral, elaborando convenções sistêmicas, apropriando-se de conhecimentos oriundos das artes estáticas e dinâmicas e lutando por se consolidar como um gênero artístico. O movimento mecânico dos bonecos, associado à ideia de uma onipresença que os coordenava, continuava sendo apresentado como uma metáfora, no qual a ação dos bonecos era utilizada como representação da ação humana, favorecendo tanto o reconhecimento do grotesco que existe em nós quanto os questionamentos filosóficos sobre nossa condição. Podemos supor que, por essa razão, e pela ilusão de que um ser inanimado possa ganhar vida, o tradicional Teatro de Bonecos tenha preservado os anteparos que mantiveram o homem, a força motriz do boneco, longe das vistas do público durante muito tempo. 


\section{Metamorfoses do século XX}

No decorrer de sua evolução, e em constante busca para o desenvolvimento das especificidades de sua linguagem, a prática teatral concedeu ao boneco a árdua tarefa de esmerar-se em ser "um substituto do personagem dramático, no qual os gestos e a voz provém de um bonequeiro inteiramente dissimulado aos olhos do público" (Jurkowsky, 2008, p. 15). Mas, num processo de reavaliação das especificidades dessa arte, a partir do final do século XIX e primeiros anos do século XX, com uma vanguarda artística que envolvia pintores e escultores (não apenas marionetistas profissionais), o teatro de bonecos se renovou e rebelou-se com a situação de subserviência e reprodução da arte teatral dos atores humanos que o havia marcado no século XIX (Jurkowsky, 2008, p. 19-21). Nesse momento, a natureza do teatro de bonecos já havia influenciado as reflexões de Heinrich von Kleist e Richard Wagner, ainda no século XIX e, a seguir, de Maurice Maeterlinck, Adolphe Appia e de Edward Gordon Craig, no início do século XX. As ideias desses artistas, insatisfeitos com a intromissão demasiada humana na obra artística, foram revolucionárias do ponto de vista de uma abertura para novas perspectivas de apreciação do boneco como modelo de atuação para o ator. Se o boneco imitara o homem, havia chegado o momento de sua revanche. Segundo Odette Aslan (1994), a formação tradicional do ator, "tributária do patrimônio clássico", preocupada com o "falar bem" e o "colocar-se bem", embasada no culto aos grande atores e num empirismo, assim como o sistema de Stanislavsky, compreendidos entre o período de 1850 e 1950, já não correspondiam aos anseios artísticos, e as novas formulações punham em crise o naturalismo. A ascensão do simbolismo, do dadaísmo, do surrealismo, do expressionismo e do futurismo, foi decisiva como fator para a eclosão de uma nova visão teatral, mais abstrata, na qual a presença do ator e a primazia do texto já não constituíam o epicentro. Aslan afirma que:

\footnotetext{
No século passado, o ator preparava o seu papel sem levar em conta o espaço, entrando no cenário na véspera ou na antevéspera da estreia; era sempre mais ou menos uma mesma configuração cênica à italiana. Hoje, arruma-se o espaço e insere-se nele o ator do mesmo modo que os outros elementos do espetáculo, seja esse espaço confortável ou não ao ator; separa-se cada vez menos os atores dos espectadores (Aslan, 1994, p. XIX).
}

Notadamente, o advento da Modernidade trouxe significativas ideias sobre a arte, influenciando também o campo da animação e repercutiram, mais tarde, nas teorias pós-modernas. O período pós-guerra, a partir da segunda metade do século $\mathrm{XX}$, é reconhecido como um período de novas experimentações para os artistas da animação teatral, que buscaram investigar novas técnicas, contaminando-as com outras formas de arte. Nesta época, percebe-se uma renovação em relação aos modos de apresentação dos espetáculos. Henryk Jurkowsky (2008, p. 83-112) aponta uma ruptura radical com a poética do teatro de bonecos tradicional, distinguindo nele elementos heterogêneos que passaram a coexistir no espetáculo teatral de bonecos. Constata-se que, progressivamente, a partir dos anos 1950 e 1960, segundo os estudos de Jurkowsky, no teatro de bonecos, a manifestação de um personagem já não se encontrava somente sintetizada em um "boneco", enquanto forma escultó- 
rica antropomórfica, mas também poderia estar contida tanto em um objeto de uso cotidiano quanto em um material dúctil ou efêmero e até mesmo o próprio corpo humano, ou parte deste. O fato de que a matéria animável na cena teatral poderia ser praticamente tudo causou indagações profundas sobre a natureza dessa arte e sobre sua denominação terminológica. Com o surgimento de toda uma gama de modalidades, o próprio termo "teatro de bonecos" começou a ser questionado tanto quanto a ideia de que ele era um gênero que deveria preservar sua "pureza". Dessa forma, não sendo mais satisfatória para representar uma categoria, essa terminologia passou a ser vista por muitos artistas como redutora do potencial expressivo e limitadora das criações artísticas investigativas. Afim de dar conta da ampliação dessas possibilidades criativas, novas terminologias foram cunhadas e, no Brasil, particularmente, foram difundidos mais amplamente os termos "teatro de animação" e "teatro de formas animadas", com o intuito de provocar uma expansão no entendimento das especificidades da linguagem, a partir dos estudos publicados pela pesquisadora Ana Maria Amaral (1991), que contribuíram nas discussões sobre a incorporação desse olhar mais descentrado das concepções ligadas à figura do boneco tradicional. Assim, o uso dessas terminologias colaborou para identificar o traço distintivo da linguagem em uma prática ou postura percebida na cena teatral, a qual poderia apresentar, ou não, um objeto fisicamente (Piragibe, 2011, p.15).

Em nosso milênio, ao verificarmos o uso das novas tecnologias ${ }^{2}$ cada vez mais frequente nas práticas artísticas que se utilizam da animação, intuímos que possa existir uma nova maneira de refletir sobre as especificidades do teatro de animação, bem como de apreender e utilizar os recursos cênicos que ele nos propõe, pois, sabemos que cada tecnologia desenvolvida modifica algumas dimensões da nossa inter-relação com o mundo, da percepção da realidade, da interação com o tempo e com o espaço. Nessa ótica, a investigação do espaço virtual pelo artista pode redimensionar a arte e as relações de significância que o corpo humano, dentro da obra artística, suscitariam. Lúcia Santaella nos lembra que:

[...] o que as novas tecnologias colocam em movimento, o que elas transformam são as "fronteiras do humano". Essa transformação se revela sob vários pontos de vista: os limites que definem o que é propriamente humano e o que os diferencia dos não-humanos (natureza/artifício, orgânico/inorgânico); os limites que o habitam e o constituem (matéria/espírito) e os limites que diferenciam a experiência imediata e suportada por sua corporeidade biológica, natural e territorial e a experiência mediada por artefatos tecnológicos (presença/ausência, real/simulacro, próximo/longínquo). (Santaella, 2008, p. 29)

Em consideração às transformações apontadas por Santaella, talvez a maior e mais perceptível mudança sofrida no teatro de animação contemporâneo, além da incorporação de novas tecnologias e surgimento de novas modalidades de operação do objeto animado, seja justamente a dinâmica de ocupação do espaço cênico pelo

\footnotetext{
2 São chamadas de Novas Tecnologias de Informação e Comunicação (NTICs) as tecnologias e métodos utilizados na comunicação, progressivamente desenvolvidos a partir da segunda metade da década de 1970 e, principalmente, nos anos 1990. Essas tecnologias informacionais obtiveram tamanho vulto no panorama social que seu aparecimento corresponde à chamada Revolução Informacional, Revolução Telemática ou Terceira Revolução Industrial. Em sua maioria, as NTICs fazem com que o conteúdo da comunicação torne-se menos palpável, transformando a informação em bits, aumentando sua velocidade de transmissão, distribuição e capacidade de armazenamento.

Fonte: http://pt.wikipedia.org/wiki/Novas_tecnologias_de_informação_e_comunicação. Acesso em: 04 jul. 2013.
} 
ator. Seu corpo, cada vez mais visível na cena, passa a penetrar e transitar intensamente nas camadas ficcionais que envolvem o objeto animado, alternando seu status dentro da diegese e aumentando as possibilidades de entrelaçamento dramatúrgico. Com isso, a complexidade do ambiente circundante do ator é exacerbada, podendo reelaborar o conceito de cenografia e dando abertura aos chamados dispositivos cênicos aparentes, os quais se opõem aos tradicionais mecanismos de ocultamento do ator animador. Nos aspectos relativos à plástica e engenharia construtiva dos objetos animados, a elaboração dos mecanismos de animação incorporou novos materiais produzidos pela indústria bem como novas tecnologias de ferramental, aliando-os aos processos tradicionais de confecção. Nas últimas décadas, vemos mais frequentemente o uso de computadores, joysticks, micro-motores e servos mecânicos e elétricos em cena, com o fim de operacionalizar e animar objetos, o que pode resultar tanto numa maior percepção de autonomia do objeto quanto em novos meios de integração com o corpo do ator, como no caso de animatrônicos 3 .

Se, por um lado, hodiernamente, temos o objeto ou boneco animado trafegando confortavelmente entre concepções que o enaltecem como objeto ilusional de autonomia e entre concepções que o lançam como material performático para o ator, por outro lado, também temos concepções em que o objeto é utilizado potencialmente como símbolo, metáfora para a narrativa. Jean-Luc Mattéoli (2009) observa essa característica do teatro de animação contemporâneo, pautada no uso de material "recuperado", ou seja, "reciclado": matéria-prima de segunda mão, objetos destinados para fins primeiros diversos que o fim teatral (tais como utensílios, ferramentas, brinquedos ou bibelôs). O uso de material descartado para criar novas formas, salvando-os do desuso para insuflar-lhes uma "segunda vida", segundo Mattéoli, é o domínio do objeto "pobre", desprovido de todo valor de sua utilidade corrente. O autor destaca que, no panorama teatral, desde os anos 1970 esta tendência vem ganhando força, a partir do trabalho desenvolvido por Tadeuz Kantor.

Dessa forma, percebemos que as obras artísticas contemporâneas, destacadamente aquelas que envolvem o teatro de animação, exigem do artista o conhecimento das especificidades de sua arte tanto quanto podem exigir o domínio de interfaces possíveis com outros campos. Os avanços científicos na área da biotecnologia, da nanotecnologia, da robótica e da medicina molecular, entre outros, nos fazem repensar a natureza humana e a interação desta com seu habitat. O corpo artificial, artificializado, não mais o orgânico, passa a ser uma forte referência para a pesquisa cênica e as descobertas sobre os processos psicofísicos do funcionamento do corpo e sobre a manifestação da vida incitam novas criações artísticas. De fato, não há como negar que essas descobertas e transformações de paradigmas afetam toda a concepção de uma arte na qual a vida, sua representação e projeção no objeto inanimado constituem material de estudo.

3 Bonecos, próteses ou máscaras que se movimentam por meio de eletrônica e robótica, sob o comando de um operador humano. 0 que os difere do robô é que a animação do animatrônico é realizada em tempo real, enquanto que os movimentos do robô podem ser programados e não necessitam da presença do operador para serem realizados. Inicialmente desenvolvidos para utilização em cinema e televisão, hoje também ocupam a cena teatral. 


\section{Teatro de Bonecos no Brasil...ou Teatro de Animação?}

No Brasil, temos a década de 1970 como um marco da história do teatro de bonecos. O movimento associativo dos "bonequeiros" brasileiros, iniciado em 1973 com a criação da ABTB - Associação Brasileira de Teatro de Bonecos, filiada à UNIMA - Union International de la Marionnette, reuniu artistas bonequeiros e colaborou para a formação e aperfeiçoamento profissional. Clorys Daly, uma das fundadoras da ABTB comenta que:

[...] parece que foi ontem que um grupo de 13 jovens idealistas, alguns já nem tão jovens assim, se reuniu no dia 27 de abril de 1973 com a finalidade de criar a Associação Brasileira de Teatro de Bonecos. A fundação da Associação se tornava imperativa depois da realização consecutiva de três festivais de marionetes e fantoches no Rio de Janeiro, o que despertou a atenção dos Diretores da UNIMA para os acontecimentos no mundo dos títeres no Brasil. Daquele momento em diante sentimos a importância de criar uma associação para estabelecer um efetivo intercâmbio cultural com a conceituada entidade internacional ${ }^{4}$.

Nas décadas que se seguiram, uma série de ações foram propostas com o intuito de difundir o conhecimento nesta área e provocar reflexões sobre o estado dessa arte. Dentre essas ações, a Revista Mamulengo (1973-1982), uma revista dedicada ao teatro de bonecos do Brasil, patrocinada pelo Serviço Nacional de Teatro (MEC), publicada pela ABTB e distribuída gratuitamente para seus sócios, foi uma importante contribuição para a difusão e discussão dessa arte, haja vista a carência de publicações em português que havia no período.

Se, nos anos 1980, os efeitos dessa movimentação já eram percebidos pela crescente instituição de novos núcleos regionais afiliados à $A B T B-U N I M A$, tais como a AGTB - Associação Gaúcha de Teatro de Bonecos, co-responsável pela criação de um dos maiores festivais nacionais do período, o Festival Internacional de Teatro de Bonecos de Canela, na década de 1990 podemos notar, sob a influência dos frutuosos intercâmbios realizados, a participação de artistas e técnicos provindos de outras áreas afins, de variadas regiões do Brasil e de outros países, possibilitando novos olhares e orientações distintas a respeito do objeto teatral animado. Também, neste período, percebemos a crescente busca pela formação e aperfeiçoamento dos artistas e das companhias por meio da realização de cursos, intercâmbios e participação em outros festivais internacionais. Em contrapartida, a produção artística brasileira em teatro de bonecos adquire maior vulto internacional. A homenagem prestada ao Brasil no 10 Festival Mondial des Théâtres des Marionnettes, em Charleville-Mézières, em 1994, através da exposição Marionnettes en Territoire Brésillien (com bonecos do grupo Mamulengo Só-Riso, de Pernambuco ${ }^{5}$ ) e da apresentação de várias companhias brasileiras dentro da programação oficial do festival, colaborou na abertura de um mercado internacional para nossa produção artística. Outro exemplo de ação efetiva, que reverberou na qualidade da produção brasileira, foi a iniciativa de criação do Centro Latino-americano de Teatro de Bonecos, na Aldeia de Arcozelo

4 Disponível no site: http://abtb-centrounimabrasil.blogspot.com.br/2013/03/parabens-feliz-40-aniversario.html - Acesso em: 11 jul. 2013.

50 currículo dessa companhia encontra-se disponível em:

http://www.itaucultural.org.br/aplicexternas/enciclopedia_teatro - Acesso em: 12 jul. 2013. 
(RJ), uma parceria da FUNARTE, ABTB e UNIMA. O projeto, embora tenha resistido pouco tempo, foi pioneiro por propor residências intensivas que viabilizavam intercâmbio de conhecimentos entre os artistas. Todos esses movimentos na década de 1990 colaboraram na geração de variadas orientações dentro do teatro de animação brasileiro. Essas orientações amplificaram o entendimento dessa arte e geraram novas possibilidades de experimentações na constituição do sujeito da cena e em suas relações com o espaço. Os artistas intensificaram as experimentações concernentes aos aspectos heterogêneos em suas produções, mesclando distintas áreas artísticas num mesmo espetáculo, e incorporaram tecnologias a serviço de ideias e expressões interiores dos criadores, autores, encenadores e atores.

Se refletirmos especificamente sobre a produção brasileira, notaremos que o teatro de animação se proliferou intensamente nas últimas décadas, tanto do ponto de vista quantitativo quanto qualitativo. Ou, pelo menos, podemos notar que diversas produções teatrais apropriaram-se de recursos da animação. Podemos, assim, identificar a proliferação tanto no número de produções teatrais quanto no número de festivais que surgiram e que se dedicam a organizar uma programação que apresente espetáculos vinculados a essa arte . $^{6}$

Nesse contexto, o trabalho do ator de animação expandiu-se e se tornou múltiplo dentro das novas proposições advindas de pesquisa de linguagem, pois o ator, ao modificar sua relação com o espaço, sentiu necessidade de elaborar outro modo de interpretar. Nesse "outro modo", do qual participa uma escuta, ou percepção, constante dos materiais expressivos que o entornam, o ator teve que empreender um diálogo eloquente com esses materiais, no sentido de gerar expressividade, embasado numa técnica corporal que o auxiliasse na construção de imagens potencializadas para expressar e conduzir seu trabalho. $O$ ator, ao elaborar essas imagens, relacionando seu corpo com o objeto e com o espaço, fabrica composições dramatúrgicas e atua na dinamização imagética do público, executando partituras de ações nas quais se manifesta o espetacular. Essas partituras funcionam como frases, como narrativa, como texto que reverbera no espaço. Felisberto Sabino da Costa diz que

essa ideia de diálogo, ampliada para além da palavra, urde todos os elementos que compõe a dramaturgia cênica. No teatro de animação, esse princípio, aplicado ao ator-animador, estabelece uma relação entre corpo e objeto, que mutuamente se atravessam. (Costa, 2011, p.41)

Costa ainda diz que "o teatro de animação deve tornar vivo, ao invés de reproduzir o vivo", ele deve "estabelecer circuitos de relações sonoras/visuais e sinestésicas" (Costa, 2011, p.46). Com isso, o autor nos fala de uma dramaturgia fundada na sensação do espectador, que atravessa seus sentidos. Uma dramaturgia do ritmo, da imagem, do som, do corpo em relação com o espaço-tempo. Para Max Reinhardt,

a partitura, e não o drama, é o texto cênico que se representa. Esta partitura é a que define os conteúdos e as intenções concretas do espetáculo cênico. E a elaboração da partitura é um exercício dramatúrgico no qual a preocupação pelo verbal e pelo

6 Como no caso do SESI Bonecos do Brasil e do Mundo (Festival Itinerante), FITA Floripa (SC), FITB - Festival Internacional de Teatro de Bonecos (MG), Festival Internacional de Teatro de Bonecos de Canela (RS), Boneco Gira Boneco - Festival Internacional de Teatro de Bonecos (SP), entre outros. 
dramático seguem cedendo terreno para nivelar-se cada vez mais com o resto das linguagens anotadas nela ${ }^{7}$. (Reinhardt apud Sánchez, 2002, p.42, tradução nossa)

Muitas produções brasileiras utilizam a visualidade como motor para a elaboração de dramaturgia, fazendo com que cada alteração de luz, cada textura, cada cor ou movimento de objetos adquira um significado contextual e fazendo com que o confronto entre a manifestação das formas inanimadas e o ator humano enfatize questões metafóricas e filosóficas, expressando relações de simbiose, de enfrentamento, de subserviência, de opressão e de duplicação de identidade, entre outras. A busca por ascender a este universo mítico, através do jogo teatral, estimula, pela imaginação, o universo criativo do espectador.

Percebemos hoje, nos grandes festivais e circuitos nacionais e internacionais realizados no Brasil, duas tendências espetaculares. Numa delas, o tradicional teatro de bonecos, que mantém o ator oculto e se utiliza do boneco como forma tridimensional antropomorfizada ${ }^{8}$.

Já na outra vertente ${ }^{9}$, temos tendências experimentais que buscam um sentido mais amplo na animação teatral, experimentando novos jogos relacionais entre atores, bonecos, objetos de cena e outras linguagens, em situações heterógenas, segundo a definição de que o teatro de animação heterógeno é aquele em que o boneco não é mais o elemento dominante e sim um componente entre outros (Jurkowsky, 2008, p. 15).

Seria redutor definir apenas duas vertentes, ainda mais categorizá-las em tradicionais e contemporâneas, visto que elas estão intimamente interligadas e oferecem várias conformações e entrelaçamentos. Não entraremos, portanto, nessa discussão. Apenas alertamos, com a exemplificação acima, que falar da produção brasileira em teatro de animação é adentrar um território imenso que se estende em variadas direções. Tanto as temáticas desenvolvidas pelos espetáculos quanto as técnicas utilizadas e as poéticas adotadas apresentam um amplo panorama. Aqui, partimos dos pressupostos de que a arte da animação de objetos (que compreende os bonecos em amplo sentido) não está dissociada da arte teatral como um gênero apartado, e de que ela pode fornecer à encenação, através de recursos que estimulam a imaginação mítica, uma ferramenta provocadora de teatralidade, entendendo a teatralidade segundo o estudo de Josette Féral (2003), o qual apresenta o termo como um atributo de uma ação, não exclusiva do teatro, mas percebido por um observador que, de alguma forma, aciona a fricção entre a realidade e a ficção.

\footnotetext{
7 "La partitura, y no el drama, es el texto escénico que se representa. Esta partitura es la que define contenidos y las intenciones concretas del espectáculo escénico. Y la elaboración de la partitura es un ejercicio dramatúrgico, en el cual la preocupación por lo verbal y lo dramático siguen cediendo terreno para nivelarse cada vez más con el resto de los lenguajes anotadas en ella."

8 Nesta forma, como exemplo mais característico, podemos citar o Mamulengo, o Casemiro Coco, o Calunga, o João Redondo, o João Minhoca, para citar alguns exemplos mais ligados à tradição dos festejos populares. Em outros trabalhos, que utilizam variantes, também persiste uma forte referência no tradicional. Exemplos característicos dessa forma são encontrados nos trabalhos do grupo TIM - Teatro Infantil de Marionetes (RS), da família Sena, nos espetáculos Bonecrônicas e Bonecomédias, do grupo AnimaSonho (RS), Histórias da Carrocinha, da companhia Caixa do Elefante (RS), Tribuliço, da companhia Lumbra (RS), Sob a Luz da Lua, da companhia Gente Falante (RS) e A bela adormecida, da companhia Giramundo (MG), entre outros.

9 Podemos citar alguns trabalhos como exemplo, entre eles, Coquetel Clown, do grupo XPTO (SP), Bichos do Brasil, do grupo Pia Fraus (SP), Nau, um poema cênico, do grupo Filhos da Lua (PR), Babel, Formas e Trans-Formações, do Grupo Casulo (SP), e Sangue Bom, da companhia PeQuod (RJ).
} 


\section{À guisa de uma conclusão}

Sob uma perspectiva que propõem o "diálogo", a interação sígnica dos elementos teatrais (ator, cenários, objetos de cena, luz, som, figurinos), gerando zonas de tensionamentos e significâncias provocadas por percepções plurais de presenças interpretadas como sujeitos, entendemos que o ator, o objeto e o espaço podem se relacionar e configurarem sentidos múltiplos e alternados, manifestando conflitos em forma de metáforas visuais ao apresentarem a realidade física do corpo vivo do ator em interação com a ânima fictícia atribuída ao objeto em cena. Nesse entendimento, é a análise dos elementos em conjunto, como fatores indissociáveis, que revelam a natureza de suas existências ficcionais.

De um modo mais amplo, em contraposição à ideia de que a interpretação do ator animador é projetada no objeto e mediada por ele, como ocorre mais frequentemente no entendimento do tradicional teatro de bonecos, temos a ideia de que a interpretação do ator animador é elaborada a partir de uma relação íntima com o objeto e seu entorno, envolvendo a compreensão de aspectos físicos e psicológicos para a estruturação de um novo corpo ficcional, dotado de específicos e próprios significantes, amalgamado pela simbiose do corpo do ator em relação com os demais elementos através da ação. Ou seja, o conceito de "desdobramento projetivo" (Bensky, 2000), no qual a interpretação do ator abriga-se no objeto como um ente deslocado de seu próprio corpo e que passa a representá-lo, não parece ser suficiente para dar conta da complexidade que envolve nossas produções contemporâneas. A análise do contexto global da cena também merece atenção para a determinação dessas presenças ficcionais, avaliando a qualidade e a forma da relação estabelecida entre o ator, os objetos e o espaço, que pode intercambiar suas funções cênicas ${ }^{10}$.

Ao longo dessas análises, concluímos então que a terminologia Teatro de Animação revela uma maior aptidão para destacar uma presença desdobrada do ator, a qual pode reverberar em distintas funções exercidas simultaneamente; ocupando espaços imaginários sobrepostos; comportando-se ao mesmo tempo como dois corpos diferentes que coexistem, simulando duas autonomias alternadamente; ou, ainda constituindo um sujeito múltiplo a partir da associação de elementos. Isto revela uma acepção distinta sobre trabalho do ator contemporâneo em relação à concepção do trabalho do ator no Teatro de Bonecos tradicional.

Assim, nessa reflexão, esperamos alargar o entendimento sobre a animação teatral e as qualidades que a podem definir. Ao considerar a produção teatral brasileira ratificamos que a empreitada é uma tarefa vasta e complexa e por isso optamos em analisar apenas alguns aspectos de sua poética, tais como a presença de atores visíveis que contracenam ou utilizam bonecos ou objetos animados; a significância atribuída ao espaço cênico e o modo especial com o qual os atores se relacionam com ele, construindo dramaturgia principalmente através de metáforas visuais e da fisicalidade.

10 Anne Ubersfeld (2010, p. 118) nos apresenta a ideia de que o espaço teatral é ocupado por elementos concretos (corpos dos atores, elementos do cenário e acessórios) e que "esses elementos merecem o nome de objetos", pois, para ela, as funções desses elementos, na cena, podem ser intercambiáveis. 


\section{Referências}

AMARAL, Ana Maria. Teatro de formas animadas. São Paulo: EDUSP, 1991.

ASLAN, Odette. O ator no século XX. São Paulo: Perspectiva, 1994.

BENSKY, Roger-Daniel. Recherches sur les structures et la symboliques de la marionete. Paris: Nizet, 2000.

CARRIGNON, Christian; MATTÉOLLI, Jean-Luc. Le Théâtre d'objet. Paris: Éditions THEMAA, 2009.

COSTA, Felisberto Sabino da. A poética do ser e não ser: procedimentos dramatúrgicos do teatro de animação. São Paulo, 2000. Tese (Doutorado). USP

FÉRAL, Josette. Acerca de la teatralidad. Cuadernos de teatro XXI. Buenos Aires: Nueva Generación, 2003.

JURKOWSKI, Henryk. Métamorphoses: la marionnette au XXe siècle. Charleville -Mézières: Institut International de la Marionnette, 2008.

MAGNIN, Charles. Histoire des marionnettes en Europe: depuis l'antiquité jusqu'à nos jours. Paris: Michel Lévy Frères, 1862. $2^{\underline{a}}$ ed.

PIRAGIBE, Mário Ferreira. Manipulações: entendimentos e usos da presença e da subjetividade do ator em práticas contemporâneas de teatro de animação no Brasil. Rio de Janeiro, 2011. Tese (Doutorado). UNIRIO

SANCHEZ, José A. Dramaturgias de la imagen. Cuenca: Ediciones de la Universidad, 2002.

SANTAELLA, Lúcia. Corpo e comunicação: sintoma da cultura. São Paulo: Paulus, 2004.

Recebido em: 30/04/2015

Aprovado em: 16/04/2016 